\title{
Profit shifting in Brazil and the impact of tax havens
}

\author{
Alex A. T. Rathke ${ }^{1}$ \\ (D) https://orcid.org/0000-0003-0397-8904 \\ Email: alex.rathke@alumni.usp.br \\ 1 Universidade de São Paulo, Faculdade de Economia, Administração e Contabilidade de Ribeirão Preto, Departamento de Contabilidade, \\ Ribeirão Preto, SP, Brazil
}

Received on 06.17.2019 - Desk acceptance on 07.19.2019 - $3^{\text {rd }}$ version approved on 11.14.2019 - Ahead of print on 05.11.2020

Editor-in-Chief: Fábio Frezatti

Associate Editor: Eliseu Martins

\begin{abstract}
We investigate tax-induced profit shifting in Brazil and the impact of tax havens on the shifting behavior of firms. Profit shifting research in Brazil is virtually non-existent, although the shifting incentives in Brazil are prominent. Our research fills this gap with evidences in the novel Brazilian context. Profit shifting is a tax-minimization strategy where multinational enterprises perform intra-firm transactions to allocate taxable profits to low-tax locations. Brazil combines a remarking set of profit shifting incentives, especially a high corporate tax rate, extremely complex tax system, and distinguished transfer pricing rules. Further researches may leverage from the shifting incentives in Brazil, since it provides opportunities to investigate additional factors that affect the shifting behavior of firms. We analyze 989 transaction-by-country observations for the period of 2010-2017. Baseline analysis follows the robust least squares approach with controlling covariates. Linear estimate model derives from the conventional Cobb-Douglas production function, to analyze the impact of shifting incentives on profit maximization. We find that Brazilian firms have a high level of intra-firm transactions with related parties located in low-tax countries, especially with tax havens. It represents a strong evidence of profit shifting behavior in Brazilian firms.
\end{abstract}

Keywords: profit shifting, transfer pricing, tax havens, base erosion and profit shifting (BEPS). 


\section{INTRODUCTION}

Profit shifting is a well-known tax avoidance strategy where multinational enterprises (MNE) perform transactions with foreign related parties, thus to transfer taxable profits from high-tax to low-tax countries. One of the most traditional profit shifting channels refers to the manipulation of transfer prices, when companies make tax-induced adjustments on intra-firm prices. A key advantage of the profit-shifting strategy is that taxable profits are not hidden or omitted, but they are merely allocated to a specific country with a low-tax rate. Existing studies provide relevant evidences of profit shifting by means of direct transfer-pricing manipulation (Bartelsman \& Beetsma, 2003; Bernard, Jensen, \& Schott, 2006; Clausing, 2003; Cristea \& Nguyen, 2016; Davies, Martin, Parenti,\& Toubal, 2018; Overesch, 2006; Swenson, 2001).

Governments worldwide are long-time aware about the harming effects of profit shifting and have historically implemented several mechanisms to curb this practice. The predominant approach established by the Organization for Economic Co-operation and Development (OECD) states that transfer prices must comply with the arm's length principle for they must be comparable with the prices established under independent conditions (OECD, 2013, 2017). In spite of this requirement, some studies show that MNE are able to exploit weaknesses and blindspots in countries' tax rules, thus to distort transfer prices (Beer \& Loeprick, 2015; Davies et al., 2018). Furthermore, MNE are able to override the anti-shifting rules by taking advantage of the so called "tax havens", which are jurisdictions with favorable tax regimes and weak tax enforcement, which usually have little to none tax provisions on transfer prices (Desai, Foley, \& Hines, 2006; Dharmapala, 2014; Lohse, Riedel,\& Spengel, 2012). In this case, the MNE can shift taxable profits away from the high-tax countries while reducing the chances of penalization from the host countries.

Profit shifting is one of the most fundamental research subjects in the international tax literature, especially on accounting and economics and current researchers accumulate striking evidences on that account (Beer, de Mooji,\& Liu, 2018; Heckemeyer \& Overesch, 2017; Knoll \& Riedel, 2014; Riedel, 2018). Some initial studies analyze profit shifting on an aggregate level, focusing on the influence of cross-country tax differentials and the patterns of internal trades and firms' global profitability (Desai et al., 2006; Dharmapala \& Riedel, 2013; Heckemeyer \& Overesch, 2017; Taylor \& Richardson,
2012). Further studies obtain more direct evidences by means of direct inspection of intra-firm transactions. Results show that differences between the arm's length prices and intra-firm transfer prices vary systematically with tax differentials (Bartelsman \& Beetsma, 2003; Bernard et al., 2006; Clausing, 2003; Cristea \& Nguyen, 2016; Davies et al., 2018; Overesch, 2006; Swenson, 2001). For a comprehensive review of the current profit shifting research, see Dharmapala (2014), Beer et al. (2018), and Riedel (2018).

Despite being a well-established subject in tax literature, profit shifting research in Brazil is virtually non-existent. The only study dedicated to investigate international profit shifting in Brazil is the one of Rathke (2014), which finds that Brazilian firms are able to transfer taxable profits away from Brazil, therefore resulting in a reduction of the total tax burden of the Brazilian consolidated group. Brazil provides a favorable context for the profit shifting research, since it combines an extremely high corporate taxation, one of the most complex tax systems in the world (Jacob, 2018), and the most distinguished set of transfer pricing (TP) rules in the world (Lohse et al,, 2012). In special, the Brazilian TP rules do not follow the arm's length principle, which is the main principle applied by the OECD guidelines worldwide (Lohse et al., 2012). Several abnormal regulatory characteristics follow from this distinction, e.g., TP methods that are inconsistent with the OECD guidelines, arbitrary safe-harbor regimes, absence of effective mutual agreement procedures, and no provisions referring to permanent-establishment status.

This study investigates tax-induced profit shifting in Brazil and analyses the impact of tax havens on the shifting behavior. We follow the traditional approach and identification strategies developed by the current profit shifting literature and apply them to the novel Brazilian context. Data includes Brazilian listed firms for the period 2010-2017 that publish information about intrafirm transactions in their annual financial statements. Results show that Brazilian firms have higher volume of transactions with related parties located in countries with lower tax rates, i.e., for two foreign countries, results show that Brazilian firms have higher volume of intrafirm transactions with the country that applies the lower income tax rate. This result is a strong evidence of profit shifting in Brazil, since firms are able to shift taxable profits to foreign countries by means of both mispricing and volume factors (Clausing, 2000; Riedel, 2018). Moreover, our results show that Brazilian firms have an incremental 
volume of intra-firm transactions with related parties located in tax havens. It suggests that the Brazilian firms are still attracted by the favorable tax conditions offered by tax havens, and the stylized TP requirements established in Brazil are not sufficient to completely curb the profit shifting.

We obtain original evidences of profit shifting in Brazil, for this is the main contribution of this study. Existing researches are applied mostly to firms located in the United States of America and in the European countries, on which the TP rules follow the international OECD standards and represent a stringent regulation. We obtain relevant results from the novel Brazilian context, where the domestic TP rules are arbitrary and do not follow the traditional arm's length principle (Lohse et al., 2012). Brazil has one of the highest tax burdens in the world (Jacob, 2018), and our findings endorse the intuitive perception that Brazilian firms shift taxable profits to low-tax countries. This motivates us to advance on the investigation of the shifting behavior of firms, thus to further develop the profit shifting research in Brazil.

The remaining of this study is structured as follows: section 2 presents a model for the profit shifting incentive, section 3 describes the data and identification strategy, section 4 presents the results, and section 5 concludes.

\section{A SIMPLE MODEL ON THE PROFIT SHIFTING INCENTIVES}

Our model is based on the "concealment costs" approach (Allingham \& Sandmo, 1972; Kant, 1988; Yitzhaki, 1974) which is based on the expected utility theory (von-Neumann \& Morgenstern, 1953). Overall, this theory establishes the main axioms that support the maximization decisions under risk and infers that the value attributed for the outcomes of the risky decisions is the expected utility of the decision maker, based on her own evaluations. The expected utility theory is a mainstream microeconomic theory that explains the incentives that influence the behavior under risk. The concealment costs approach is built on the expected utility theory, and is the most traditional approach in profit shifting literature (Beer et al., 2018; Davies et al., 2018).

Consider two wholly owned divisions of a vertically integrated MNE located in different countries, $\{i, j\}$ each producing outputs $x_{\mathrm{i}}$ under costs $C_{\mathrm{i}}\left(x_{\mathrm{i}}\right)$, bringing revenues $R_{\mathrm{i}}\left(s_{\mathrm{i}}\right)$ from sales $s_{\mathrm{i}}\left(x_{\mathrm{i}}\right)$. Moreover, one of the divisions $i$ sells a share of its outputs $m$ to the other division $j \neq i$, charging a transfer price $p$ established by the MNE's headquarter. Assume that the intra-firm output $m$ depends on the market demand $x_{j}$ for the final product of the purchaser division. The pre-tax profits of both divisions are

$$
\begin{gathered}
\pi_{i}=R_{i}\left(s_{i}\right)-C_{i}\left(s_{i}+m\right)+p m ; \\
\pi_{j}=R_{j}\left(s_{j}\right)-C_{j}\left(s_{j}-m\right)-p m, j \neq i .
\end{gathered}
$$

For simplification, assume that the MNE is subjected to the source principle for the taxation of foreign profits, and no incremental costs are incurred on transfers of intrafirm outputs $m$. For an income tax rate $\tau_{\mathrm{i}} \in[0,1]$ in each country, the baseline global net profits for both divisions is equal to $\Pi=\left(1-\tau_{\mathrm{i}}\right) \pi_{\mathrm{i}}+\left(1-\tau_{\mathrm{j}}\right) \pi_{\mathrm{j}}$. Profit shifting incentives arise if the tax rates between divisions are different, $\tau_{\mathrm{i}} \neq \tau_{\mathrm{j}}$, and global net profits $\Pi$ increases if the MNE is able to manage intra-firm transactions $p m$ thus taxable profits are transferred from the high-tax country to the low-tax country. In special, MNE has discretion in determining the transfer price $p$, therefore the maximizing condition

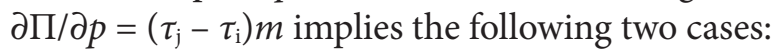

Low-transfer-price case (LTP):

$\tau_{j}<\tau_{i} \rightarrow \frac{\partial \Pi}{\partial p}<0$;

High-transfer-price case (HTP):

$\tau_{j}>\tau_{i} \rightarrow \frac{\partial \Pi}{\partial p}>0$.

For the LTP case, the MNE has incentives to charge a low transfer price $p$ thus to keep taxable profits in Country $j$, which harms tax revenues in Country $i$. In the HTP case, the MNE maximizes global profits $\Pi$ by choosing a high transfer price $p$, so to shift taxable profits to Country $i$ and harming Country $j$.

In this scenario, both countries implement domestic anti-shifting measures to prevent the intra-firm mispricing. The conventional regulatory approach requires that the transfer price $p$ must comply with the price $\bar{p}$ determined under the arm's length condition (OECD, 2017). Any price deviations $\Delta p=p-\bar{p}$ are assessed by tax authorities in both countries, which may impose nondeductible penalties if they understand that the difference $\Delta p$ represents enough evidence of profit shifting. Hence, assume that each country implement a set of domestic tax rules, such that $\forall i, j, D_{\mathrm{i}}(\Delta p): \mathrm{R} \rightarrow\{0,1\}, \Delta p=0 \rightarrow D_{\mathrm{i}}=0$ is a characteristic map which triggers a tax penalty if the price deviation $\Delta p$ is considered a sufficient evidence of profit shifting under these rules. In the case of penalization, the harmed country requires the payment of the amount of 
evaded taxes $\tau_{i} \cdot \Delta \mathrm{pm}$ plus a penalty rate $z_{\mathrm{i}}>0$ over this amount (Yitzhaki, 1974). Therefore, the tax penalty cost is represented by a function $Z_{\mathrm{i}}\left(D_{\mathrm{i}}(\Delta p) \tau_{\mathrm{i}} \cdot \Delta p m \cdot\left(1+z_{\mathrm{i}}\right)\right)$.

Assume that the arm's length price $\bar{p}$ is the same for all matters, such that both countries are not simultaneously harmed; it allows us to drop the divisions' indexes hereinafter for simplification. Therefore, the final maximization object is equal to

$$
\Pi_{z}=\Pi-Z(D(\Delta p), \tau \cdot \Delta p m \cdot(1+z)), \forall i, j
$$

For the tax differential $\Delta \tau=\tau_{j}-\tau_{i}$, the optimal transfer price $p^{*}$ is obtained at the maximization level where the marginal gains of profit shifting are equal to the marginal penalization costs,

$$
\begin{gathered}
\frac{\partial \Pi_{Z}}{\partial p}=\Delta \tau \cdot m-\frac{\partial Z}{\partial D} \cdot \frac{d D}{d(\Delta p)} \cdot \tau \cdot(1+z) \cdot m=0 \\
\Delta \tau=\frac{\partial Z}{\partial D} \cdot \frac{d D}{d(\Delta p)} \cdot \tau \cdot(1+z) .
\end{gathered}
$$

This is the fundamental equation of the optimal tax-induced TP. Notice that the marginal penalization costs at the right hand side of the equality follow the sign of the profit shifting direction, $\Delta \tau$, since the sign of the price deviation $\Delta p$ indicates which country is being harmed, i.e., LTP case implies $\Delta \tau<0, \Delta p<0 \rightarrow z=z_{\mathrm{i}}, d D / d(\Delta p)<0$, whiletheHTP caseimplies $\Delta \tau>0, \Delta p>0 \rightarrow z=z_{\mathrm{j}}, d D / d(\Delta p)>0$. In simple terms, it means that profit shifting always provides a global (non-negative) gain, regardless if it refers to LTP or HTP case, and this gain is increasing up to the optimal transfer price $p^{*}$. It proofs the following:

Proposition 1: tax-induced manipulations of transfer prices always increase the global net profits of the MNE up to the optimal transfer price $p^{*}$.

In the implicit form of $p^{*}\left(D^{-1}, \Delta \tau, z\right)$, the inverse characteristic map $D^{-1}:\{0,1\} \rightarrow \mathrm{R}$ refers to the general effect of the domestic tax rules of the harmed country; note that it is not theoretically necessary for each $D(\Delta p)$ or $D^{-1}$ to be bijective mappings.

The MNE's main objective is to obtain maximum gains from choosing $p^{*}$. Net gains from profit shifting are computed by comparing the global net income under $p^{*}$ with the global net income under the arm's length price $\bar{p}$. We obtain the explicit equation

$$
\begin{gathered}
\Pi_{z}\left(p^{*}\right)-\Pi_{z}(\bar{p})=\Delta \tau \cdot\left(p^{*}-\bar{p}\right) m-\alpha\left(D^{-1}\right) \cdot \\
\left(\tau \cdot\left(p^{*}-\bar{p}\right) m \cdot(1+z)\right) \geq 0
\end{gathered}
$$

where $\alpha\left(D^{-1}\right) \in[0,1]$ is a cost parameter for the extent of the price deviation $\Delta p$ that is considered appropriate under the TP rules. Of course, parameter $\alpha\left(D^{-1}\right)$ is an exogenous measure that is not directly observable by the MNE and must be estimated. Generalization of the cost parameter $\alpha\left(D^{-1}, \cdot\right)$ may include the MNE's different perceptions on the uncertainties related with tax rules and tax audits and the MNE's intrinsic risk aversion (Beer et al., 2018; Dharmapala, 2014; Riedel, 2018).

The impact of domestic tax rules is reflected in the cost parameter $\alpha\left(D^{-1}\right)$. The obvious variation $\partial \alpha\left(D^{-1}\right) / \partial\left(D^{-1}\right) \leq 0$ implies that a more permissive tax rule allows for a wider price deviation $\Delta p$ before triggering the tax penalty $z$. Stricter tax rules imply the opposite.

In this line, the MNE runs a second maximization step with respect to the intra-firm output $m$. We have

$$
\begin{gathered}
\frac{\partial\left(\Pi_{z}\left(p^{*}\right)-\Pi_{z}(\bar{p})\right)}{\partial m}=\Delta \tau \cdot\left(p^{*}-\bar{p}\right)- \\
\alpha\left(D^{-1}\right) \cdot\left(\tau \cdot\left(p^{*}-\bar{p}\right) \cdot(1+z)\right) \geq 0,
\end{gathered}
$$

for it is clear that any increase in $m$ implies in an increase of the net gains from profit shifting. Therefore, the optimal level of intra-firm output $m^{*}$ depends only on the marginal rates of substitution between costs $\partial C_{\mathrm{i}} / \partial m, \forall i, j$, and the MNE is able to intensify the net gains from profit shifting by varying production schedules and manipulating inventories turnover. This result proofs the following:

Proposition 2: under optimal conditions regarding the transfer price $p^{*}$ and the marginal rates of substitution between costs $\partial C_{\mathrm{i}} / \partial m$, $\forall i, j$, increases in intra-firm outputs $m$ always increase the total amount of profit shifting, therefore increasing the global net profits of the MNE.

In summary, it is extremely convenient for the MNE to shift profits from high-tax to low-tax countries by means of TP adjustments. It is important to remark that the current international anti-shifting standards establish TP methods that are substantially flexible. Thus, it allows for a certain level of pricing abuse while still being considered appropriate by tax authorities (Beer et al., 2018; Davies et al., 2018). Moreover, the MNE has special incentives to manipulate transfer prices if it is subjected to a lenient tax regulation, for it implies a lower concealment cost, e.g., the case of tax havens. At last, MNE is able to intensify the profit shifting by means of the intra-firm outputs $m$, since there are no requirements against any amount $m$ if the transfer price $p^{*}$ is considered appropriate. These effects are equally present in both LTP and HTP cases.

This analysis yields some relevant predictions. First, it is expected that a larger tax differential between two countries is positively associated with the volume of intrafirm transactions between these two countries. It refers to 
the main profit shifting hypothesis, since a larger volume of intra-firm transactions allows the profit shifting by means of both mispricing and volume effects.

Second, it is expected that firms present a larger volume of transactions with related parties located in tax havens. This prediction reflects the widespread perception from tax practitioners and academics, that MNE make use of tax havens to reduce global taxation. This issue has received increasing importance, especially after the recent tax scandals revealed by the media, such as the Paradise Papers and the LuxLeaks, and the shifting strategies applied by companies such as Starbucks, Alphabet, and Amazon.

We focus on these predictions for the analysis of profit shifting in the Brazilian context. Factors related with high corporate taxation and intricate tax rules in Brazil provide a suitable case for investigation.

\section{DATA AND IDENTIFICATION STRATEGY}

We focus on the analysis of profit shifting in Brazilian listed firms by means of the volume of import and export transactions with related parties in other countries. Data for intra-firm transactions and firm-level covariates are obtained from firms' annual financial statements for the period of 2010-2017. The period of 2010-2017 is favorable for our analysis since it refers the worldwide implementation of the 2010 OECD's Transfer Pricing Guidelines, so our analysis is not affected by heterogeneous impacts related with the change in TP rules across countries. Likewise, we observe that the ending period of 2017 since several countries worldwide have implemented the Country-by-Country (CbC) reporting by 2018 , so our analysis is not affected by exogenous effects produced by this new tax requirement. The volume of intra-firm imports and exports are obtained for individual firms for each year segregated by country. The income tax rates across countries are obtained from the CBT Tax Database of the Oxford University Centre for Business Taxation for the period of 2010-2017. Countries are classified as tax havens for Brazilian taxation purposes according to the Brazilian tax rule Instrução Normativa da Receita Federal doBrasil (IN RFB) n. 1037/2010. All data is regarded at the yearbasis. Since Brazilian firms perform transactions with related parties located in several countries, we focus on the transaction-by-country as a unit of analysis for each year.

For the identification strategy, we follow a similar idea developed by Hines and Rice (1994), which is the baseline approach in profit shifting literature (Beer et al., 2018). Hines and Rice (1994) derive a simple estimation for the non-shifted profits based on the traditional Cobb-Douglas production function, where the firm's real output is a function of the main production factors. The standard Cobb-Douglas production function is equal to $Q=L^{\beta} K^{1-\beta}$, where $Q$ is the firm's output, $L$ and $K$ are the production factors related with labor and capital, respectively, and $\beta$ is a regularized production parameter.

As described in section 2, the profit shifting incentive arises if tax rates are different across countries; therefore the amount of intra-firm output is likely to be associated with the magnitude and the direction of the tax differential. Moreover, the existence of further tax favorable conditions for the profit shifting to arise may also affect the amount of intra-firm outputs, i.e., for $Q$ as the intra-firm output, both the tax differential $\Delta \tau$ and the taxhaven condition affect $Q$ such that $Q(\Delta \tau, T)=f(\Delta \tau) \cdot T L^{\beta} K^{1-\beta}$, where $f(\Delta \tau)$ is a function for the impact of the profit shifting incentive and $T$ is a parameter for the tax haven. Based on this design, simple linearization derives the following baseline regression model (Hines \& Rice, 1994).

$$
\log (Q)=\beta_{0}+\gamma \log (f(\Delta \tau))+\mu T+\beta_{l} X+\varepsilon
$$

where $\gamma$ is the estimate parameter for the profit shifting incentive, $\mu$ is the estimate parameter for the effect of the tax haven, $X$ is a matrix of $l$ covariates representing the $\log$ of the production factors, and $\beta_{1}$ is a vector for the parameters of the covariates. Production factors include labor costs, firms' resources invested in productive assets and inventories turnover, and fixed sector parameters for the effect of industry technology; these are the traditional production factors related with the operational outputs of the firm (Hines \& Rice, 1994). Covariates also include macroeconomic indicators for each country related with the GDP and distance, thus to account for the effect of the economic activity of each country. Indexes for firm, year, and country are absent from the regression equation for simplification. Our analysis focuses on the volume of intra-firm output as the dependent variable, thus to conform with the core of the Cobb-Douglas approach.

We apply the baseline regression model for our investigation. We expect to find both estimate coefficients $\gamma$ and $\mu$ to be positive. 


\section{ANALYSIS}

This section presents the descriptive statistics, the baseline regression results for the profit shifting in Brazil, and a set of complementary analyses.

\subsection{Descriptive Statistics}

\section{Table 1}

Descriptive statistics

\begin{tabular}{|c|c|c|c|c|c|}
\hline Variables & Obs. (n) & Mean & SD & Min. & Max. \\
\hline \multicolumn{6}{|l|}{ Firm-level } \\
\hline $\begin{array}{l}\text { Volume of intra- } \\
\text { firm transactions }\end{array}$ & 989 & 468.4 & $4,030.7$ & 0.0 & $57,026.0$ \\
\hline Labor expenses & 648 & $1,180.23$ & $2,263.61$ & 2.1 & $29,732.1$ \\
\hline PPE & 989 & $4,926.0$ & $32,768.3$ & 0.0 & $629,830.9$ \\
\hline Inventories - Net & 987 & $1,864.2$ & $3,118.3$ & 3.6 & $29,057.2$ \\
\hline Revenues - Net & 989 & $17,479.0$ & $36,270.2$ & 245.7 & $321,638.0$ \\
\hline Assets - Total & 989 & $19,163.5$ & $52,835.9$ & 145.8 & $900,135.1$ \\
\hline $\begin{array}{l}\text { Capital } \\
\text { expenditures }\end{array}$ & 984 & $1,033.3$ & $4,198.3$ & 3.0 & $71,311.0$ \\
\hline Liabilities - Total & 989 & $12,593.6$ & $35,738.6$ & 74.1 & $645,403.9$ \\
\hline $\begin{array}{l}\text { Costs and expenses } \\
\text { - Total }\end{array}$ & 989 & $15,801.0$ & $33,250.5$ & 226.8 & $259,224.0$ \\
\hline \multicolumn{6}{|l|}{ Country-level } \\
\hline $\begin{array}{l}\text { Income tax rate- } \\
\text { Foreign }(\%)\end{array}$ & 336 & 27.0 & 8.1 & 0.0 & 35.0 \\
\hline Tax differential (\%) & 336 & 7.0 & 8.1 & -1.0 & 34.0 \\
\hline $\begin{array}{l}\text { GDP (US\$ } \\
000.000 .000)\end{array}$ & 336 & $3,903.2$ & $5,963.3$ & 3.4 & $19,390.6$ \\
\hline GDP ratio (US\$) & 336 & 1.8 & 2.8 & 0.0 & 10.4 \\
\hline $\begin{array}{l}\text { Distance from } \\
\text { Brazil - Regularized }\end{array}$ & 42 & 0.4072 & 0.2411 & 0.0672 & 1.0000 \\
\hline Foreign countries $(\mathrm{n})$ & 42 & & & & \\
\hline Tax havens (n) & 18 & & & & \\
\hline Years (n) & 8 & & & & \\
\hline Industries (n) & 7 & & & & \\
\hline
\end{tabular}

Note: This table presents the descriptive statistics for the firm-level and country-level variables. All variables are obtained at a yearbasis. All firm-level variables are presented in millions of Brazilian reals ( $R \$ 000.000)$. Volume of intra-firm transactions refer to the sum of the amount of import and export transactions with related parties, for each sample firm, for each year. Revenues refer to the total revenues from sales minus sales deductions. All firm-level variables are obtained from the firms' annual financial statements. Country-level variables are presented according to the type of variable. Tax differential refers to the difference between the Brazilian marginal tax rate of $34 \%$ and the income tax rate on the country of the related party, for each year. Annual gross domestic product (GDP) ratio refers to the ratio between the GDP of the foreign country and the GDP in Brazil, for each year. Data for GDP by country is obtained from the Organization for Economic Co-operation and Development (OECD) Statistics database. Distance from Brazil is regularized on the range $[0,1]$. Countries are classified as tax havens according to the Brazilian tax rule Instrução Normativa da Receita Federal do Brasil (IN RFB) n. 1037/2010. Since firms perform intra-firm transactions with related parties in several countries, we obtain a repeated-firm database; we focus on the transaction-by-country as a unit of analysis. Additional details on the data are presented in section 3.

$P P E=$ net balances of plant, property and equipment; $S D=$ standard deviation.

Source: Elaborated by the author. 
Table 1 presents the descriptive statistics for the firmlevel and country-level data. We obtain a total of 989 transaction-by-country observations for the complete period of 2010-2017. Some variables are not available for all observations, e.g., labor expenses and inventories. Preliminary analysis of the descriptive numbers provides some insights about the data structure. We observe that the volume of intra-firm transactions has a wide variation range, with the max amount on about 14 times the standard deviation. This strongly suggests the existence of outliers in our sample. Moreover, Table 1 shows that the income tax rate across countries has a mean of $27 \%$, and it varies within the range of (0.0-35.0\%). It indicates that the Brazilian marginal tax rate of $34 \%$ is among the highest tax rates of our sample; therefore, it reinforces the existence of shifting incentives for Brazilian firms.

\subsection{Baseline Results}

We first compute the estimate coefficients for the baseline model derived in section 3 omitting the parameter for tax havens $T$, thus to address the influence of the fundamental profit shifting incentive $\Delta \tau$ on the volume of intra-firm transactions. Traditional production factors refer to labor expenses, fixed assets and inventories (Hines \& Rice, 1994). All firm-level covariates are regularized with respect to total net revenues or total assets, to allow for comparability (details in Table 2 further). Hence, estimates are computed with respect to the monotone transformation $\log (1+$ variable $)$ for the regularized variables, so to account for the constraints of the logtransformation range. Moreover, we include industry-level and country-level controls in our estimates. Since we have a repeated-firm database, the homogeneous year-level effects are captured by the firm-level covariates.

Notice that the descriptive statistics in Table 1 suggest the existence of potential outliers in our sample. We apply the traditional Bonferroni adjustment on studentized residuals on preliminary estimates, which reveals the existence of 10 outlier observations in our sample. These outliers are dropped from our analyses from now on. Initial results are presented in Table 2.

Table 2

Regression estimates - Profit shifting incentive $\Delta \tau$

\begin{tabular}{|c|c|c|c|c|c|c|c|c|}
\hline \multirow[b]{2}{*}{ Variables } & \multicolumn{8}{|c|}{ Estimate coefficients: $\gamma, \beta_{l}$} \\
\hline & 1 & & 2 & & 3 & & 4 & \\
\hline \multirow{2}{*}{ Tax Param.: $\log (f(\Delta \tau))=\Delta \tau$} & 0.1330 & $*$ & 0.1404 & $*$ & 0.1683 & $*$ & 0.1917 & $*$ \\
\hline & 0.0404 & & 0.0411 & & 0.0466 & & 0.0292 & \\
\hline \multirow{2}{*}{ Labor expenses } & -0.0394 & & -0.0230 & & -0.0418 & & -0.0285 & \\
\hline & 0.0228 & & 0.0252 & & 0.0234 & & 0.0249 & \\
\hline \multirow{2}{*}{ PPE } & 0.0723 & $*$ & 0.0081 & & 0.0720 & $*$ & 0.0065 & \\
\hline & 0.0228 & & 0.0283 & & 0.0231 & & 0.0191 & \\
\hline \multirow{2}{*}{ Inventories } & -0.1061 & & -0.0142 & & -0.1070 & & -0.0102 & \\
\hline & 0.0599 & & 0.0495 & & 0.0594 & & 0.0457 & \\
\hline Industry-level controls & $\mathrm{N}$ & & $\mathrm{Y}$ & & $\mathrm{N}$ & & $\mathrm{Y}$ & \\
\hline Country-level controls & $\mathrm{N}$ & & $\mathrm{N}$ & & $\mathrm{Y}$ & & $\mathrm{Y}$ & \\
\hline Observations (n) & 638 & & 638 & & 638 & & 638 & \\
\hline F-statistics & 16.30 & $* *$ & 14.33 & $* *$ & 12.27 & $* *$ & 13.37 & $* *$ \\
\hline R-squared adjusted & 0.0877 & & 0.1730 & & 0.0959 & & 0.1889 & \\
\hline
\end{tabular}

Note: This table presents the estimate coefficients $\gamma_{1} \beta_{1}$ for the baseline regression model, excluding outlier observations from the sample. Numbers in plain refer to the estimate coefficients. Numbers in italic refer to the estimates'standard errors. Standard errors are obtained from the Whitess covariance matrices to account for heteroscedastic consistency. Outliers are selected based on the traditional Bonferroni adjustment on studentized residuals of initial baseline estimates. Derivation of the baseline model is presented in section 3. Details about all variables are presented in section 3 and Table 1. Column 1 presents the estimate coefficients with no controls for industry or country effects. Column 2 includes industry-level fixed controls only. Column 3 includes country-level controls only. Column 4 includes industry-level and country-level effects. Variables related with the amount of intra-firm transactions and labor expenses are regularized with respect to the total net revenues for each firm, for each year. Variables related with plant, property and equipment (PPE) and inventories are regularized with respect to the total assets for each firm, for each year. Estimates are computed with respect to the monotone transformation log $(1+v a r i a b l e)$ for the dependent variable and the firm-level covariates. Fixed controls for industry effects refer to an indicator variable for the firm's industry sector. Controls for country effects refer to the ratio between annual gross domestic product (GDP) of the foreign country and the annual GDP in Brazil, and the distance between Brazil and the foreign country.

$N=n o ; Y=$ yes.

*t statistic significative at $<0.01$ level; ** F-statistic significative at $<0.01$ level.

Source: Elaborated by the author. 
The estimate coefficient $\gamma$ for the variable of interest $\Delta \tau$ is significative in magnitude and direction for all cases presented in Table 2, thus supporting the profit shifting hypothesis. It indicates that Brazilian firms have a larger volume of intra-firm transactions with related parties located in jurisdictions with lower income tax rates. Remark that discounting the regularizations and log transformation of variables, we obtain the effect

$$
\frac{d Q}{Q+R}=\gamma \cdot d \Delta \tau
$$

where $R$ is the total net revenues for each firm, individual indexes omitted. Therefore, Table 2 suggests that a variation of $1 \%$-unit in the tax differential produces a semi-elasticity effect of about 13 -to-19\% on average over the volume of intra-firm transactions with respect to the total amount of firms' transactions and sales. This result is significative for variations in industry-level and country-level controls.

We may explore how the estimate coefficient $\gamma$ in Table 2 behaves after some additional variations in the model. Firstly, we remark that the estimates in Table 2 assume the equality $\log (f(\Delta \tau))=\Delta \tau$ for simplification. In this sense, we can apply the monotone transformation $\log (f(\Delta \tau))=\log (1+\Delta \tau)$ for the tax differential as well, consistent with the other transformed parameters. Also, we compute the estimate coefficients by direct linear regression with respect to all regularized parameters. At last, we apply the inverse transformation $1 /(\tau+0.1)$ as in Grubert and Mutti (2000) for the foreign tax variable $\tau$, thus to analyze the magnified effect of very low-tax rates on profit shifting (Azémar, 2010; Clausing, 2000; Grubert $\&$ Mutti, 2000). The new estimates $\gamma$ ' obtained from each specification are presented in Table 3.

Table 3

Regression estimates - Profit shifting incentive $\Delta \tau$, model variations

\begin{tabular}{|c|c|c|c|c|c|c|c|c|}
\hline \multirow[b]{2}{*}{ Tax Param.: $\log (f(\Delta \tau))$} & \multicolumn{8}{|c|}{ Estimate coefficient: $\gamma^{\prime}$} \\
\hline & 1 & & 2 & & 3 & & 4 & \\
\hline \multirow{3}{*}{ 1. $\log (1+\Delta \tau)$} & 0.1428 & $*$ & 0.1497 & $*$ & 0.1845 & $*$ & 0.2096 & $*$ \\
\hline & 0.0280 & & 0.0444 & & 0.0510 & & 0.0327 & \\
\hline & $(13.37)$ & $* *$ & (14.09) & $* *$ & $(12.01)$ & $* *$ & (13.18) & ** \\
\hline \multirow{3}{*}{ 2. $\Delta \tau$, direct linear reg. } & 0.1571 & $*$ & 0.1666 & $*$ & 0.1962 & $*$ & 0.2245 & $*$ \\
\hline & 0.0490 & & 0.0502 & & 0.0565 & & 0.0344 & \\
\hline & (16.78) & $* *$ & (14.48) & $* *$ & $(12.37)$ & $* *$ & (13.36) & ** \\
\hline \multirow{3}{*}{ 3. $1 /(\tau+0.1)$} & 0.0105 & $*$ & 0.0112 & $*$ & 0.0114 & $*$ & 0.0131 & $*$ \\
\hline & 0.0033 & & 0.0034 & & 0.0035 & & 0.0037 & \\
\hline & $(17.02)$ & $* *$ & $(15.02)$ & $* *$ & $(12.15)$ & $* *$ & (13.28) & ** \\
\hline Firm-level covariates & $\mathrm{Y}$ & & $\mathrm{Y}$ & & Y & & $\mathrm{Y}$ & \\
\hline Industry-level controls & $\mathrm{N}$ & & $\mathrm{Y}$ & & $\mathrm{N}$ & & $\mathrm{Y}$ & \\
\hline Country-level controls & $\mathrm{N}$ & & $\mathrm{N}$ & & Y & & $\mathrm{Y}$ & \\
\hline Observations (n) & 638 & & 638 & & 638 & & 638 & \\
\hline
\end{tabular}

Note:This table presents the estimate coefficients $\gamma^{\prime}$ for the variations in the model specification, excluding outlier observations from the sample. Numbers in plain refer to the estimate coefficients $\gamma^{\prime}$. Numbers in italic refer to the estimates' standard errors. Numbers in parentheses refer to the Fstatistic of each regression. Standard errors are obtained from the White's covariance matrices to account for heteroscedastic consistency. Outliers are selected based on the traditional Bonferroni adjustment on studentized residuals of preliminary baseline estimates. Derivation of the baseline model is presented in section 3 . Details about all variables are presented in section 3 and Table 1 . Row 1 refers to the baseline model assuming $\log (f(\Delta \tau))=\log (1+\Delta \tau)$. Row 2 refers to the estimates obtained from direct linear regression with respect to the regularized parameters, assuming log $(f(\Delta \tau))=$ $\Delta \tau$. Row 3 refers to the baseline model assuming $\log (f(\Delta \tau))=1 /(\tau+0.1)$, where $\tau$ is the marginal tax rate of the foreign country. Column 1 presents the estimate coefficients with no controls for industry or country effects. Column 2 includes industry-level fixed controls only. Column 3 includes country-level controls only. Column 4 includes industry-level and country-level effects. All estimates include the effect of firm-level covariates according to each model specification. Fixed controls for industry effects refer to an indicator variable for the firm's industry sector. Controls for country effects refer to the ratio between annual gross domestic product (GDP) of the foreign country and the annual GDP in Brazil and the distance between Brazil and the foreign country. $N=$ no; $Y=$ yes.

${ }^{*}$ t statistic significative at $<0.01$ level; ${ }^{* *}$ F-statistic significative at $<0.01$ level.

Source: Elaborated by the author. 
We observe that all estimate coefficients $\gamma^{\prime}$ in Table 3 are significative in magnitude and direction, regardless of the specification applied. As expected, results are quantitatively consistent with the baseline estimates $\gamma$ in Table 2. For example, for the new estimates based on the monotone transformation $\log (\mathrm{f}(\Delta \tau))=\log (1+\Delta \tau)$ presented in Table 3, row 1 , we derive the equality $\gamma=\gamma^{\prime} /(1+\Delta \tau)$. The estimate coefficient $\gamma^{\prime}$ in Table 3 , row 1 , column 1 , is equal to $\gamma^{\prime}=0.1428$. In this case, assuming an average tax differential effect of $\overline{\Delta \tau}=0.07$ computed in the descriptive statistics, we have an average effect of $0.1428 /(1.07)=0.1335$, which is quantitatively equivalent to the corresponding baseline estimate $\gamma=0.1330$ presented in Table 2. This is true for all specifications in Table 3. Hence, the estimates from the alternative specifications presented in Table 3 are consistent.
Advancing in our analyses, we investigate the effect of tax havens on the volume of intra-firm transactions. We compute the estimate coefficients for the full baseline model in Section 3 and Table 2, and for the alternative specifications as presented in Table 3, i.e., by applying the monotone transformation $\log (f(\Delta \tau))=\log (1+\Delta \tau)$, running the direct linear regression for all regularized parameters and applying the inverse transformation $1 /(\tau+0.1)$. Now, we expect to find both estimate coefficients $\gamma$ and $\mu$ to be positive, which refer to the coefficients of the profit shifting incentive $\Delta \tau$ and the tax haven parameter $T$, respectively, for each of the specifications applied. Firm-level covariates are the same as in the initial estimates in Table 2. All estimates include industry-level and country-level controls and exclude the outliers identified in the preliminary analyses. Estimates are presented in Table 4.

Table 4

Regression estimates - Profit shifting incentive $\Delta \tau$, tax haven parameter $T$

\begin{tabular}{|c|c|c|c|c|c|c|c|c|}
\hline \multirow[b]{2}{*}{ Variables } & \multicolumn{8}{|c|}{ Estimate coefficients: $\gamma, \mu$} \\
\hline & 1 & & 2 & & 3 & & 4 & \\
\hline \multirow{2}{*}{ Tax Param.: $\log (f(\Delta \tau))$} & 0.1769 & $*$ & 0.1938 & $*$ & 0.0116 & $*$ & 0.2070 & * \\
\hline & 0.0473 & & 0.0518 & & 0.0035 & & 0.0578 & \\
\hline \multirow{2}{*}{ Tax Haven Param.: $T \in\{0,1\}$} & 0.0214 & $*$ & 0.0216 & $*$ & 0.0201 & $*$ & 0.0255 & * \\
\hline & 0.0053 & & 0.0053 & & 0.0052 & & 0.0063 & \\
\hline Firm-level covariates & $\mathrm{Y}$ & & $\mathrm{Y}$ & & $\mathrm{Y}$ & & $\mathrm{Y}$ & \\
\hline Industry-level controls & $\mathrm{Y}$ & & Y & & $\mathrm{Y}$ & & Y & \\
\hline Country-level controls & $\mathrm{Y}$ & & $\mathrm{Y}$ & & $\mathrm{Y}$ & & $\mathrm{Y}$ & \\
\hline Observations (n) & 638 & & 638 & & 638 & & 638 & \\
\hline Obs. tax havens (n) & 392 & & 392 & & 392 & & 392 & \\
\hline F-statistics & 14.52 & $* *$ & 14.39 & $* *$ & 14.14 & $* *$ & 0.1457 & $* *$ \\
\hline R-squared adjusted & 0.2163 & & 0.2146 & & 0.2114 & & 0.2169 & \\
\hline
\end{tabular}

Note:This table presents the estimate coefficients $\gamma, \mu$ for the baseline regression model and variations, excluding outlier observations from the sample. Numbers in plain refer to the estimate coefficients. Numbers in italic refer to the estimates' standard errors. Standard errors are obtained from the White's covariance matrices to account for heteroscedastic consistency. Outliers are selected based on the traditional Bonferroni adjustment on studentized residuals of preliminary baseline estimates. Derivation of the baseline model is presented in section 3. Details about all variables are presented in section 3 and Table 1. Column 1 presents the estimate coefficients for the baseline model assuming $\log (f(\Delta \tau))=\Delta \tau$. Column 2 presents the estimates for the baseline model assuming $\log (f(\Delta \tau))=\log (1+\Delta \tau)$. Column 3 presents the estimates obtained from direct linear regression with respect to the regularized parameters, assuming $\log (f(\Delta \tau))=\Delta \tau$. Column 4 presents the estimates for the baseline model assuming $\log (f(\Delta \tau))=1 /(\tau+0.1)$, where $\tau$ is the marginal tax rate of the foreign country. Tax haven parameter $T$ refers to an indicator variable with value 1 if the foreign related country is located in a tax haven and 0 otherwise. Countries are classified as tax havens according to the Brazilian tax rule Instrução Normativa da Receita Federal do Brasil (IN RFB) n. 1037/2010. All estimates include the effect of firm-level covariates according to each model specification. Fixed controls for industry effects refer to an indicator variable for the firm's industry sector. Controls for country effects refer to the ratio between annual gross domestic product (GDP) of the foreign country and the annual GDP in Brazil and the distance between Brazil and the foreign country. $Y=$ yes.

* t statistic significative at $<0.01$ level; **F-statistic significative at $<0.01$ level.

Source: Elaborated by the author.

Results show that both estimate coefficients $\gamma$ and $\mu$ are significative for each of the specifications presented in
Table 4. First, we observe that the profit shifting incentive $\Delta \tau$ has a relevant magnitude effect after isolating the 
influence of tax havens. It means that Brazilian firms are able to perform intra-firm transactions to shift profits away from Brazil even if the destination country is not a tax-favorable location. This result corroborates the theoretically prediction, since the Brazilian marginal tax rate equal to $34 \%$ is close to the max tax rate of $35 \%$ of our sample, and it is substantially higher than the global average income tax rate of $27 \%$ (Table 1). Existing studies show that firms shift profits low-tax countries due to the taxhaven status, and they indicate the absence of profit shifting to general countries if the tax incentive $\Delta \tau$ is weak (Davies et al., 2018). Our findings provide the complementary evidences about the presence of profit shifting to general countries if the incentive $\Delta \tau$ is strong.

Second, we observe that the tax haven effect $T$ is significative, thus indicating that Brazilian firms have a higher volume of intra-firm transactions with related parties located in tax havens. Since $T$ is a discrete parameter, overall results in Table 4 suggest that the taxhaven status of the destination country produces a semi-elastic increment of about $2 \%$ on average over the volume of intra-firm transactions with respect to the total amount of firms' transactions and sales. Besides, close inspection of the outcomes in Table 4 shows that the estimate coefficients $\gamma$ and $\mu$ are reasonably consistent in magnitude with the baseline analyses in Table 2, e.g., in Table 4, column 1, the estimates $\gamma=0.1769$ and $\mu=0.0214$ imply a combined mean effect of $\gamma+\mu=0.1983$, while the corresponding estimate coefficient in Table 2, column 4, presents the combined effect of 0.1917 .

In summary, results in tables 2-4 indicate that Brazilian firms have a substantially larger volume of transactions with related parties located in countries with lower tax rates. Moreover, Brazilian firms have an incremental volume of intra-firm transactions with related parties in tax havens. Results are significative in magnitude and direction for all variations in our model, and the estimate coefficients are quantitatively consistent across all specifications. Our findings represent a strong set of evidences on the profit shifting practice in Brazil. This is consistent with current evidences, especially in Davies et al. (2018) and Beer and Loeprick (2015), which show that a significant portion of the firms' profits are shifted by means of tax havens.

\subsection{Complementary Analyses}

Our baseline findings follow from the theoretical developments presented in section 2. We explore some further variations in the identification strategy. Firstly, remark that the "blacklist" in the Brazilian tax rule IN RFB n. 1037/2010 defines two groups of tax havens: the first includes countries that are classified as tax havens under absolute state, while the second group includes countries that are considered tax havens if some conditions are satisfied. These conditions refer mostly to the legal characteristics of the foreign company. In this scenario, we adjust the baseline model to include two mutually exclusive parameters $T$ and $T$ ' for the taxhaven status. Assume the discrete parameter $T$ referring to countries classified as tax havens in absolute, and the discrete parameter $T$ ' referring to tax havens if the conditions in the Brazilian tax rule are satisfied. We expect to find at least one of the estimate coefficients $\mu$ or $\mu$ ' to be positive, which refer to the effect of parameters $T$ and $T$, , respectively, for each of the specifications applied. Results are presented in Table 5.

\section{Table 5}

Regression estimates - Profit shifting incentive $\Delta \tau$, tax haven parameters $T$ and $T^{\prime}$

\begin{tabular}{|c|c|c|c|c|c|c|c|c|}
\hline \multirow[b]{2}{*}{ Variables } & \multicolumn{8}{|c|}{ Estimate coefficients: $\gamma, \mu, \mu^{\prime}$} \\
\hline & 1 & & 2 & & 3 & & 4 & \\
\hline \multirow{2}{*}{ Tax Param.: $\log (f(\Delta \tau))$} & 0.1300 & $*$ & 0.1408 & $*$ & 0.0079 & $* *$ & 0.1466 & * \\
\hline & 0.0331 & & 0.0362 & & 0.0033 & & 0.0377 & \\
\hline \multirow{2}{*}{ A.Tax Haven Par.: $T \in\{0,1\}$} & 0.0457 & $*$ & 0.0474 & $* *$ & 0.0427 & & 0.0567 & ** \\
\hline & 0.0204 & & 0.0203 & & 0.0245 & & 0.0250 & \\
\hline \multirow{2}{*}{ C.Tax Haven Par.: $T^{\prime} \in\{0,1\}$} & 0.0175 & $*$ & 0.0174 & $*$ & 0.0173 & $*$ & 0.0204 & * \\
\hline & 0.0052 & & 0.0052 & & 0.0052 & & 0.0061 & \\
\hline Firm-level covariates & $\mathrm{Y}$ & & $\mathrm{Y}$ & & $\mathrm{Y}$ & & $\mathrm{Y}$ & \\
\hline Industry-level controls & Y & & Y & & Y & & Y & \\
\hline Country-level controls & Y & & Y & & Y & & Y & \\
\hline Observations (n) & 638 & & 638 & & 638 & & 638 & \\
\hline Obs. A.Tax Havens (n) & 57 & & 57 & & 57 & & 57 & \\
\hline
\end{tabular}


Table 5

Cont.

\begin{tabular}{|c|c|c|c|c|c|c|c|c|}
\hline \multirow[b]{2}{*}{ Variables } & \multicolumn{8}{|c|}{ Estimate coefficients: $\gamma, \mu, \mu^{\prime}$} \\
\hline & 1 & & 2 & & 3 & & 4 & \\
\hline Obs. C.Tax Havens (n) & 335 & & 335 & & 335 & & 335 & \\
\hline Fstatistics & 14.04 & $* * *$ & 14.01 & *** & 13.44 & $* * *$ & 14.20 & *** \\
\hline R-squared adjusted & 0.2227 & & 0.2224 & & 0.2146 & & 0.2249 & \\
\hline
\end{tabular}

Note: This table presents the estimate coefficients $\gamma, \mu, \mu^{\prime}$ for the variations in the baseline model, excluding outlier observations from the sample. Numbers in plain refer to the estimate coefficients. Numbers in italic refer to the estimates' standard errors. Standard errors are obtained from the White's covariance matrices to account for heteroscedastic consistency. Outliers are selected based on the traditional Bonferroni adjustment on studentized residuals of preliminary baseline estimates. Derivation of the baseline model is presented in section 3. Details about all variables are presented in section 3 and Table 1. Column 1 presents the estimate coefficients for the baseline model assuming $\log (f(\Delta \tau))=\Delta \tau$. Column 2 presents the estimates for the baseline model assuming $\log (f(\Delta \tau))=\log (1+\Delta \tau)$. Column 3 presents the estimates obtained from direct linear regression with respect to the regularized parameters, assuming $\log (f(\Delta \tau))=\Delta \tau$. Column 4 presents the estimates for the baseline model, assuming $\log (f(\Delta \tau))=$ $1 /(\tau+0.1)$, where $\tau$ is the marginal tax rate of the foreign country. A. Tax Haven parameter $T$ refers to an indicator variable with value 1 if the foreign related country is classified as an absolute tax haven and 0 otherwise. C. Tax Haven parameter $T^{\prime}$ refers to an indicator variable with value 1 if the foreign related country is classified as a conditional tax haven and 0 otherwise. Countries are classified as absolute or conditional tax havens according to the Brazilian tax rule Instrução Normativa da Receita Federal do Brasil (IN RFB) n. 1037/2010. All estimates include the effect of firm-level covariates, according to each model specification. Fixed controls for industry effects refer to an indicator variable for the firm's industry sector. Controls for country effects refer to the ratio between annual gross domestic product (GDP) of the foreign country and the annual GDP in Brazil and the distance between Brazil and the foreign country.

$Y=$ yes.

* $t$ statistic significative at $<0.01$ level; ** $t$ statistic significative at $<0.05$ level; *** Fstatistic significative at $<0.01$ level.

Source: Elaborated by the author.

Results in Table 5 ratify the impact of tax havens on the shifting behavior of Brazilian firms. Either estimate coefficients $\mu$ or $\mu$ ' are positive and significative for each of the specifications, for it shows an incremental volume of intra-firm transactions with related parties located in tax havens of one type or the other. Besides, the estimate coefficient $\gamma$ for the tax differential $\Delta \tau$ is significative for all specifications in Table 5 .

Furthermore, we notice some deviations in the effects of the firm-level covariates depending on variations in the exogenous controls. Specifically, we observe that the firm-level covariates are no more significative after the inclusion of industry-specific controls in our estimates (Table 2). Therefore, we investigate if the main results remain the same after changes in the production factors in matrix $X$ within the regression model. We explore three types of firm-level covariates that may affect firms' outputs: the amount of capital expenditures, the financing structure, and the cost structure. Covariates are included at the firm-level for each firm, for each year. The effect of tax havens is set by two mutually exclusive parameters $T$ and $T$ ' for each type of tax haven. All estimates include industry-level and country-level controls. Results are presented in Table 6.

Table 6

Regression estimates - Profit shifting incentive $\Delta \tau$, tax haven parameters $T$ and $T^{\prime}$, variation in firm-level covariates

\begin{tabular}{|c|c|c|c|c|c|c|}
\hline \multirow[b]{2}{*}{ Variables } & \multicolumn{6}{|c|}{ Estimate coefficients: $\gamma, \mu, \mu^{\prime}$} \\
\hline & 1 & & 2 & & 3 & \\
\hline \multirow{2}{*}{ Tax Param.: $\log (f(\Delta \tau))=\Delta \tau$} & 0.1000 & $*$ & 0.0944 & $*$ & 0.1049 & $*$ \\
\hline & 0.0202 & & 0.0205 & & 0.0218 & \\
\hline \multirow{2}{*}{ A.Tax Haven Par.: $T \in\{0,1\}$} & 0.0282 & & 0.0320 & $* *$ & 0.0288 & ** \\
\hline & 0.0144 & & 0.0139 & & 0.0132 & \\
\hline \multirow{2}{*}{ C.Tax Haven Par.: $T^{\prime} \in\{0,1\}$} & 0.0111 & $*$ & 0.0114 & $*$ & 0.0111 & * \\
\hline & 0.0034 & & 0.0035 & & 0.0035 & \\
\hline Firm-level covariates - Type & CAPEX & & FS & & CS & \\
\hline Industry-level controls & Y & & $\mathrm{Y}$ & & Y & \\
\hline
\end{tabular}


Table 6

Cont.

\begin{tabular}{|c|c|c|c|c|c|c|}
\hline \multirow[b]{2}{*}{ Variables } & \multicolumn{6}{|c|}{ Estimate coefficients: $\gamma, \mu, \mu^{\prime}$} \\
\hline & 1 & & 2 & & 3 & \\
\hline Country-level controls & $\mathrm{Y}$ & & $\mathrm{Y}$ & & Y & \\
\hline Observations (n) & 974 & & 979 & & 979 & \\
\hline Obs. A.Tax Havens (n) & 53 & & 57 & & 57 & \\
\hline Obs. C.Tax Havens (n) & 335 & & 335 & & 335 & \\
\hline F-statistics & 18.49 & $* * *$ & 15.73 & $* * *$ & 17.21 & *** \\
\hline R-squared adjusted & 0.1774 & & 0.1742 & & 0.1773 & \\
\hline Wald test - Fstatistics & 8.19 & $* * *$ & 6.28 & $* * *$ & 6.25 & *** \\
\hline
\end{tabular}

Note: This table presents the estimate coefficients $\gamma, \mu, \mu^{\prime}$ for the regression models of different firm-level covariates in matrix $X$, excluding outlier observations from the sample. Numbers in plain refer to the estimate coefficients. Numbers in italic refer to the estimates' standard errors. Standard errors are obtained from the White's covariance matrices to account for heteroscedastic consistency. Outliers are selected based on the traditional Bonferroni adjustment on studentized residuals of preliminary baseline estimates. Derivation of the baseline model is presented in section 3. Details about all variables are presented in section 3 and Table 1. Column 1 presents the estimate coefficients including the amount of capital expenditures (CAPEX) of each firm, for each year. Column 2 presents the estimates including the components of the financial structure (FS) of each firm, for each year, and is composed by the amounts of the short-term leverage, long-term leverage, and shareholders' equity. Column 3 presents the estimates including the components of the operational cost structure (CS) of each firm, for each year, and is composed by the amounts of operational costs and operational expenses. A. Tax Haven parameter T refers to an indicator variable with value 1 if the foreign related country is classified as an absolute tax haven and 0 otherwise. C.Tax Haven parameter $T^{\prime}$ refers to an indicator variable with value 1 if the foreign related country is classified as a conditional tax haven and 0 otherwise. Countries are classified as absolute or conditional tax havens according to the Brazilian tax rule Instrução Normativa da Receita Federal do Brasil (IN RFB) n. 1037/2010. Estimates are computed with respect to the monotone transformation log $(1+$ variable) for the dependent variable and the firm-level covariates. Fixed controls for industry effects refer to an indicator variable for the firm's industry sector. Controls for country effects refer to the ratio between annual GDP of the foreign country and the annual GDP in Brazil and the distance between Brazil and the foreign country. Wald test assesses the existence of significative covariates.

$Y=$ yes.

* tstatistic significative at < 0.01 level; ** tstatistic significative at $<0.05$ level; *** F-statistic significative at $<0.01$ level.

Source: Elaborated by the author.

Results in Table 6 reinforce the main findings in section 4.2. The tax-differential effect $\Delta \tau$ is significative in magnitude and direction and is consistent across all variations presented in Table 6 . Under these specifications, results suggest that a variation of $1 \%$-unit in the tax differential produces a semi-elasticity effect of about $10 \%$ on average over the volume of intra-firm transactions with respect to the total amount of firms' transactions and sales. For the taxhaven parameters $T$ and $T$, either estimate coefficients $\mu$ or $\mu$ ' are positive and significative for each of the specifications. Results suggest an increment of about 1-to-3\% on average on the volume of intra-firm transactions, depending on the taxhaven status of the destination country.

In overall, we find strong evidences on the profit shifting strategy in Brazil. All results indicate that
Brazilian firms have a higher volume of intra-firm transactions with related parties located in low-tax countries. Moreover, Brazilian firms have an incremental volume of intra-firm transactions with related parties in tax havens. Existing studies indicate that structural differences in shifting costs across industries and countries affect the semi-elasticity effect of the tax differentials over the profit shifting behavior (Beer et al., 2018; Heckemeyer \& Overesch, 2017), so empirical estimates require the inclusion of firm-level and country-level profitability controls. In this line, we explore several variations on the empirical specification in order to obtain cautious estimates. We observe that the results in Tables 2-6 are significative in magnitude and direction, and are robust across several model specifications. 


\section{CONCLUSION}

This study provides original evidences of the profit shifting practice in Brazil. Results are solid, for they are invariant to the several robustness tests applied to the classical identification strategy.

We observe that the tax-differential effect is complemented by the taxhaven effect in Brazil, thus suggesting that the existence of slack tax requirements in foreign countries creates an additional incentive to shift profits away from Brazil. It is publicly known that the Brazilian government has a spotlight on jurisdictions with favorable tax regimes, in special those included in the Brazilian "blacklist". We observe a larger effect for the case where the classification as a tax haven is conditional to firm-level characteristics of the foreign related party. This is intuitive, since the conditional clause provides room for argumentation against a potential inquiry by the Brazilian tax authorities.

In this study, profit shifting behavior is captured by the volume of transactions of Brazilian firms with foreign related parties and with tax havens. Ideally, we would prefer to observe the transfer price directly; however, this information is not disclosed by firms, for it may represent a limitation to our investigation when compared with existing studies that analyze individual transfer price (Cristea and Nguyen, 2016; Davies et al., 2018). Nonetheless, theory shows us that the profit shifting behavior is reflected by the manipulation of both transfer prices and intra-firm outputs (Beer et al., 2018). Our findings suggest that this is the case in the Brazilian context.

Recent studies suggest that if the taxavoidance incentives are somewhat weak and the concealment costs become expressive, it becomes difficult to observe the shifting behavior of firms (Davies et al., 2018). The puzzle is to check whether profit shifting is non-existent under weak incentives, or if this is a matter of methodological limitations (Beer et al., 2018). In contrast, the Brazilian context provides a relevant set of incentives for firms to shift profits away from the country, which combines an extreme income tax rate, great complexity in tax system and a quite peculiar TP regulation. It allows more detailed analyses on the effect of different anti-shifting measures, identification of new firm-level determinants of profit shifting, and the effectiveness of multiple shifting channels by firms.

\section{REFERENCES}

Allingham, M. G., \& Sandmo, A. (1972). Income tax evasion: A theoretical analysis. Journal of Public Economics, 1(3-4), 323338.

Azémar, C. (2010). International corporate taxation and US multinationals' behaviour: An integrated approach. Canadian Journal of Economics/Revue Canadienne D'Économique, 43(1), 232-253.

Bartelsman, E. J., \& Beetsma, R. M. (2003). Why pay more? Corporate tax avoidance through transfer pricing in OECD countries. Journal of Public Economics, 87(9-10), 2225-2252.

Beer, S., \& Loeprick, J. (2015). Profit shifting: Drivers of transfer (mis) pricing and the potential of countermeasures. International Tax and Public Finance, 22(3), 426-451.

Beer, S., de Mooij, R., \& Liu, L. (2018). International corporate tax avoidance: A review of the channels, magnitudes, and blind spots. Journal of Economic Surveys, 43: 232-253.

Bernard, A. B., Jensen, J. B., \& Schott, P. K. (2006). Transfer pricing by US-based multinational firms [Working Paper]. National Bureau of Economic Research.

Clausing, K. A. (2000). The impact of transfer pricing on intrafirm trade. In International taxation and multinational activity (pp. 173-200). Chicago, IL: University of Chicago Press.

Clausing, K. A. (2003). Tax-motivated transfer pricing and US intrafirm trade prices. Journal of Public Economics, 87(9-10), 2207-2223.
Cristea, A. D., \& Nguyen, D. X. (2016). Transfer pricing by multinational firms: New evidence from foreign firm ownerships. American Economic Journal: Economic Policy, 8(3), 170-202.

Davies, R. B., Martin, J., Parenti, M., \& Toubal, F. (2018). Knocking on tax haven's door: Multinational firms and transfer pricing. Review of Economics and Statistics, 100(1), 120-134.

Desai, M. A., Foley, C. F., \& Hines, J. R., Jr. (2006). The demand for tax haven operations. Journal of Public Economics, 90(3), 513-531.

Dharmapala, D. (2014). What do we know about base erosion and profit shifting? A review of the empirical literature. Fiscal Studies, 35(4), 421-448.

Dharmapala, D., \& Riedel, N. (2013). Earnings shocks and tax-motivated income-shifting: Evidence from European multinationals. Journal of Public Economics, 97, 95-107.

Grubert, H., \& Mutti, J. (2000). Do taxes influence where US corporations invest? National Tax Journal, 53(4), 825-839.

Heckemeyer, J. H., \& Overesch, M. (2017). Multinationals' profit response to tax differentials: Effect size and shifting channels. Canadian Journal of Economics/Revue Canadienne D’Économique, 50(4), 965-994.

Hines, J. R., Jr., \& Rice, E. M. (1994). Fiscal paradise: Foreign tax havens and American business. The Quarterly Journal of Economics, 109(1), 149-182. 
Instrução Normativa RFB n. 1037/2010. Relaciona países ou dependências com tributação favorecida e regimes fiscais privilegiados. Recuperado de http:// normas.receita.fazenda.gov.br/sijut2consulta/link. action? visao $=$ anotado\&idAto $=16002$

Jacob, M. (2018). A note on tax research. Revista Contabilidade \& Finanças, 29(78), 339-342.

Kant, C. (1988). Endogenous transfer pricing and the effects of uncertain regulation. Journal of International Economics, 24(12), 147-157.

Knoll, B., \& Riedel, N. (2014). Transfer pricing laws. CESifo DICE Report, 12(4), 22-26.

Lohse, T., Riedel, N., \& Spengel, C. (2012). The increasing importance of transfer pricing regulations-a worldwide overview [Working Paper].Oxford University Centre for Business Taxation Said Business School.

Organization for Economic Co-operation and Development. (2013). Action plan on base erosion and profit shifting. Recuperado de https://www.oecd.org/ctp/BEPSActionPlan.pdf

Organization for Economic Co-operation and Development. (2017). Transfer pricing guidelines for multinational enterprises and tax administrations. Recuperado de https://www.oecd. org/tax/transfer-pricing/oecd-transfer-pricing-guidelines-formultinational-enterprises-and-tax-administrations-20769717. htm
Overesch, M. (2006). Transfer pricing of intrafirm sales as a profit shifting channel - Evidence from German firm data[Research Discussion Paper]. ZEW - Centre for European Economic.

Rathke, A. A. T. (2014). Transfer pricing e income shifting: evidências de empresas abertas brasileiras (Master's Dissertation). Universidade de São Paulo, São Paulo.

Rathke, A. A. T. (2019). Studies on transfer pricing systems and profit shifting: impact of the international regulation on the shifting behaviour of Brazilian firms (Ph.D. Thesis). Universidade de São Paulo, São Paulo.

Riedel, N. (2018). Quantifying international tax avoidance: A review of the academic literature. Review of Economics, 69(2), 169-181.

Swenson, D. L. (2001). Tax reforms and evidence of transfer pricing. National Tax Journal, 54(1)7-25.

Taylor, G., \& Richardson, G. (2012). International corporate tax avoidance practices: Evidence from Australian firms. The International Journal of Accounting, 47(4), 469-496.

von-Neumann, J., \& Morgenstern, O. (1953). Theory of games and economic behavior (3a. ed.)Princeton, NJ:Princeton University Press.

Yitzhak, S. (1974). A note on income tax evasion: A theoretical analysis. Journal of Public Economics, 3(2), 201-202. 